\title{
Possibilidades do E-Learning em Projetos Interdisciplinares no IFAC
}

\author{
Ana Carla A. Holanda ${ }^{1}$, Marcelo Almeida Bairral ${ }^{2}$ \\ ${ }^{1}$ Universidade Federal de Pernambuco (UFPE) \\ Caixa Postal 50.540-740 - Recife - PE - Brasil \\ ${ }^{2}$ Universidade Federal Rural do Rio de Janeiro (UFRRJ) \\ BR 465 Km 7 - Seropédica - RJ - Brasil \\ \{acahecin.ufpe.br, mbairraleufrrj.br\}
}

\begin{abstract}
Information and Communication Technologies (ICT) can contribute to professional education. This article is the result of a master's research that had as objectives the construction of a Virtual Learning Environment (AVA) in an interdisciplinary perspective and analysis of its contribution to the teaching and learning in the Technical course in Informatics in Campus Rio Branco Acre. With the use of direct observation, questionnaire application and postAVA analysis, the results showed that the teachers were more motivated and participative. On the part of the students we visualized a growth of the interaction and the motivation in the use of AVA. This improvement illustrates a good acceptance for the platform developed and implemented as a support for interdisciplinary work. In this sense, this research demonstrated that AVA can be an important instrument of support to interdisciplinary actions in the courses of the Federal Institutes..
\end{abstract}

Resumo. As Tecnologias da Informação e Comunicação (TIC) podem contribuir com a educação profissional. O presente artigo é fruto de uma pesquisa de mestrado que teve como objetivo a construção de um Ambiente Virtual de Aprendizagem (AVA) numa perspectiva interdisciplinar e análise de sua contribuição para o ensino e a aprendizagem no curso Técnico em Informática no Campus Rio Branco - Acre. Com o uso de observação direta, aplicação de questionário e análise de postagens no AVA, os resultados apontaram que os docentes se mostraram mais motivados e participativos. Por parte dos discentes visualizamos um crescimento da interação e da motivação na utilização do AVA. Essa melhoria ilustra uma boa aceitação para a plataforma elaborada e implementada como um apoio a um trabalho interdisciplinar. Neste sentido, esta pesquisa demonstrou que o AVA pode ser um importante instrumento de apoio a ações interdisciplinares nos cursos dos Institutos Federais.

\section{Introdução}

O uso das TIC pode contribuir para os professores na busca de uma nova maneira de ensinar. Para o aluno pode abrir diferentes possibilidade de busca de informação e de 
produção do conhecimento. A investigação que originou esse artigo se baseou na dissertação de Holanda (2014) que orientou-se pela seguinte questão: De que modo uma prática em E-Learning pautada na interdisciplinaridade pode contribuir com os processos de ensino e de aprendizagem no curso Técnico em Informática no Campus Rio Branco do Instituto Federal do Acre (IFAC)?

A Educação por E-Learning é uma das modalidades de ensino-aprendizagem, possibilitada pela mediação dos suportes tecnológicos digitais e de rede, seja esta inserida em sistemas de ensino presenciais, mistos ou completamente realizada através da distância física [Maia e Mattar 2007].

\section{O uso de ambientes virtuais em cursos técnicos}

O reconhecimento de uma sociedade cada vez mais tecnológica e digitalizada deve ser acompanhado da conscientização da necessidade de incluir nos currículos escolares habilidades para lidar com as tecnologias recentes. O professor, nesse contexto, precisa saber orientar os educandos sobre onde colher a informação, como tratá-la e como utilizála. Particularmente, com a presença cada vez mais massiva das TIC nas diferentes práticas educativas, há necessidade de uma nova postura do educador.

Nessa perspectiva, Lima (2011) sublinha que o professor é a peça-chave para que realmente essa realidade seja modificada, pois usar tecnologias modernas usando antigos padrões de metodologias, de avaliações e de postura do aluno e do professor não trará modificações na formação de um profissional dinâmico e atualizado. Logo, este é um desafio que deve ser vencido.

Assim, várias pesquisas levam em consideração a inserção da tecnologia no meio educacional. Lima (2011) mostrou que, apesar das dificuldades, a utilização de um AVA cria excelentes espaços para o processo de ensino-aprendizagem, a partir da quebra do paradigma tradicional de transmissão de conteúdos com a mudança de postura do professor, promovendo uma maior cooperação e comunicação entre alunos e professores.

Lopes (2010) narrou os resultados de uma pesquisa que investigou a adoção de um ambiente virtual de aprendizagem na disciplina presencial de informática por alunos de duas turmas em relação a outras duas turmas que não estão utilizando este meio. Observou-se que a utilização de AVA como apoio ao ensino presencial na disciplina de Informática foi considerada pelos alunos participantes uma opção bastante viável e todos os resultados das pesquisas trouxeram um ganho no aprendizado na sua utilização.

\section{Material e Métodos}

O curso escolhido foi o subsequente de Técnico em Informática que apresenta duas turmas e tem como objetivo formar um profissional especializado em desenvolvimento e manutenção de sistemas. Essas turmas foram escolhidas pelo fato de que já estarem realizando o $4^{\circ}$ período dos 6 períodos previstos e ansiavam por atividades mais voltadas para a sua área de formação.

Todos os alunos das duas turmas (41 alunos) fizeram parte do projeto realizando atividades e participando de fóruns, chats e planejamento de um sistema de informação, onde posteriormente, apresentaram um seminário com os resultados. Participaram 
VI Congresso Brasileiro de Informática na Educação (CBIE 2017)

Anais dos Workshops do VI Congresso Brasileiro de Informática na Educação (WCBIE 2017)

também os professores que ministravam disciplinas no período (08 professores). Destes, apenas 02 professores não participaram do projeto interdisciplinar.

A proposta aos docentes foi desenvolver um projeto integrador que se constituiu em um meio pedagógico para o aprimoramento da aprendizagem interdisciplinar integração e relacionamento dos conteúdos de disciplinas que compõem os semestres do curso - e, práxis - integração teoria e prática por meio da aplicação do conhecimento adquirido em sala de aula e no mundo do trabalho.

\subsection{Coleta de dados}

A coleta de dados foi feita mediante observação direta das atividades dos alunos, mediadas no Ambiente Virtual de Aprendizagem. Houve também um momento em que o perfil do grupo foi traçado a partir de um questionário. A figura 1 ilustra as etapas desenvolvidas para possibilitar a concretização da nossa proposta.

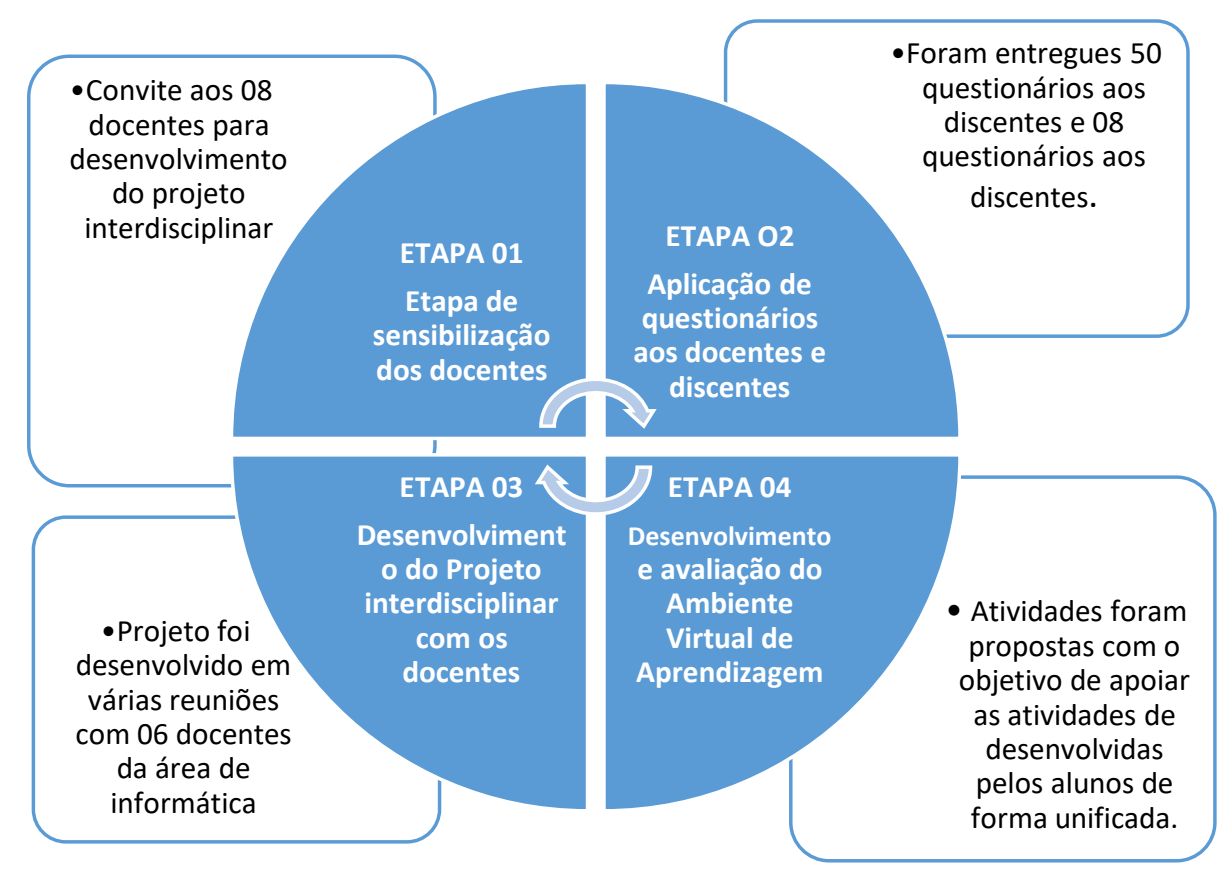

Figura 1. Etapas do desenvolvimento do projeto

\section{Análise e Discussão dos dados}

\subsection{Sobre o desenvolvimento de um projeto interdisciplinar}

Após a aplicação dos questionários foram percebidos os anseios e necessidades dos discentes das turmas pesquisadas. Verificou-se que as turmas ansiavam em realizar a interligação dos conteúdos e para atender essa necessidade foi planejado um projeto interdisciplinar com práticas que seriam realizadas em cada disciplina. Durante esta etapa, houve uma grande dificuldade em consolidar o projeto para iniciar a sua execução. Muitos e-mails e conversas com os professores foram necessárias para alinhar os objetivos e métodos que seriam utilizados na execução do projeto. 
VI Congresso Brasileiro de Informática na Educação (CBIE 2017)

Anais dos Workshops do VI Congresso Brasileiro de Informática na Educação (WCBIE 2017)

\subsection{Sobre o uso de um Ambiente Virtual de Aprendizagem}

O AVA desenvolvido no Moodle trouxe os conteúdos vistos em sala de aula de forma diferenciada, contextualizada e integrada com as demais disciplinas do curso. Nesse ambiente, o objetivo foi disponibilizar um canal diferente do que é encontrado pelo aluno em sala de aula, tendo em vista que o propósito era que o aluno tivesse interesse em acessar e participar das discussões propostas na plataforma. Ao final desta etapa, pode-se perceber que o projeto obteve o resultado esperado, levando em consideração os acessos e a interação dos alunos envolvidos, bem como a avaliação que os mesmos realizaram ao final do semestre. Além disso, um seminário final foi realizado entre todas as equipes formadas, com o objetivo de aplicar e demonstrar de forma prática o planejamento de um sistema escolhido pelas equipes.

As equipes formadas foram orientadas pelos próprios professores com o intuito de desenvolver um trabalho voltado à sistema de informação. Durante todo o semestre, os docentes estavam à disposição em encontros marcados para orientar os estudantes. $\mathrm{O}$ AVA foi fundamental para troca de experiências, comentários sobre as etapas do desenvolvimento do sistema, bem como para disponibilizar atividades com o intuito de criar no aluno uma visão mais técnica e profissional. Os discentes escolheram empresas para propor seus projetos. Realizaram o diagnóstico mediante visitas e entrevistas, analisaram necessidades e planejaram sistemas desde a base de dados ao layout. Ao final do semestre, os seminários foram marcados e todos os professores envolvidos fizeram parte da avaliação do projeto final realizados pelas equipes. Esse foi um importante de compartilhamento e consolidação de conhecimentos adquiridos.

A pesquisa reforça Costa (2009) que fala da importância da interação disciplinar quando comenta que o desafio da prática interdisciplinar envolve uma ação coletiva contextualizada de recíproca aceitação e diálogo com diversos conhecimentos, partindo do individual para o coletivo, e vice-versa, numa perspectiva holística.

Entretanto, os professores que acreditam no sucesso da prática interdisciplinar enfrentam muitos obstáculos, a começar pela ruptura de valores que se encontram enraizados em nosso interior. Sendo um projeto interdisciplinar marcado pela coletividade onde o diálogo e a troca devem estar sempre presentes, as barreiras e dificuldades surgirão, mas poderão ser transpostas pelo desejo de criar, de inovar, de ir além [Fazenda 2012].

Segundo Bairral (2009) o professor é um profissional que deve constantemente aprender a aprender e refletir criticamente sobre sua prática. O educador desempenha um papel fundamental, pois à proporção que explica os conteúdos, mantém uma permanente dialógica com os alunos.

Ao refletir sobre os resultados alcançados pode-se ressaltar que mediante estratégias do E-Learning os alunos tiveram acesso a materiais que lhes possibilitaram visualizar articulação entre conceitos. Em relação ao professor, foi compreendido que o uso da plataforma trouxe uma nova forma de planejar as suas aulas, trazendo atividades e interações difíceis de serem construídas em sala de aula. Entretanto, para isso ser possível, os professores tiveram que dispender mais tempo na construção do seu material, bem como maior dedicação no acompanhamento dos alunos envolvidos no projeto. 
VI Congresso Brasileiro de Informática na Educação (CBIE 2017)

Anais dos Workshops do VI Congresso Brasileiro de Informática na Educação (WCBIE 2017)

\section{Considerações Finais}

Ao utilizar ambientes virtuais como suporte a projetos interdisciplinares observou-se a possibilidade de utilizar importantes ferramentas para promover a comunicação entre alunos e professores, proporcionando uma maior socialização de informações e aprendizagens. Para tal, as etapas do desenvolvimento do projeto mostraram-se importantes para o êxito do projeto.

Com a implementação do AVA foi oportunizado aos envolvidos um acesso diversificado aos conteúdos, atividades e uma maior flexibilidade de tempo para o trabalho online. Quanto aos discentes percebeu-se melhorias na interação e na motivação na utilização do AVA. Apesar de dificuldades, principalmente dos docentes, para a construção do ambiente virtual e de sua deflagração na perspectiva interdisciplinar, a proposição mostrou-se frutífera para (i) a participação diferenciada e para a solidariedade dos envolvidos; (ii) para a socialização de diferentes práticas pessoais e profissionais, sem hierarquia entre as mesmas; e (iii) para a interação e reflexão continuada ao longo do processo de aprendizagem dos estudantes e professores que vivenciaram nossa proposta.

\section{REFERÊNCIAS}

BAIRRAL, Marcelo de Almeida. Pesquisa, ensino e inovação com tecnologias em educação matemática: de calculadoras a ambientes virtuais. Rio de Janeiro: Ed. da UFRRJ, 2012.

COSTA, Ronaldo Campelo da. O uso de E-portfólios na aprendizagem de alunos do Instituto Federal de Educação, Ciências e Tecnologia do Maranhão/ Campus Codó. Dissertação (Mestrado em Educação Agrícola). Instituto de Agronomia, Universidade Federal Rural do Rio de Janeiro, Seropédica, RJ. 2009.

FAZENDA, Ivani C. Arantes. Interdisciplinaridade: história, teoria e pesquisa. $18^{\mathrm{a}}$ ed. Campinas, SP: Papirus, 2012.

HOLANDA, Ana Carla A. de. O uso de estratégias de E-Learning como auxílio na implementação de práticas interdisciplinares no Instituto Federal do Acre - IFAC. Dissertação de Mestrado. Universidade Federal Rural do Rio de Janeiro. 2014.

LIMA, Claudia Bochese. Análise Dissertação Um estudo sobre a adesão de docentes do IF BAIANO Câmpus Santa Inês aos ambientes virtuais. Dissertação (Mestrado em Educação Agrícola). Instituto de Agronomia, Universidade Federal Rural do Rio de Janeiro, Seropédica, RJ. 2011

LOPES, Luis Carlos Loss. O uso de um ambiente de aprendizado virtual no apoio ao ensino presencial na disciplina de Informática no Instituto Federal do Espírito Santo Campus Santa Teresa. Dissertação (Mestrado em Educação Agrícola). Instituto de Agronomia, Universidade Federal Rural do Rio de Janeiro, Seropédica, RJ. 2010.

MAIA, C.; MATTAR, J. ABC da EAD: educação à distância hoje. São Paulo: Pearson Prentice Hall, 2007. 